\title{
Evaluation of a fourth-generation latex agglutination test for the identification of Staphylococcus aureus
}

\author{
G. I. Andriesse • S. Elberts • A. Vrolijk • C. Verhulst • \\ J. A. J. W. Kluytmans
}

Received: 27 May 2010 / Accepted: 22 September 2010 / Published online: 13 October 2010

(C) The Author(s) 2010. This article is published with open access at Springerlink.com

\begin{abstract}
In this study, we evaluated a fourth-generation agglutination assay (Staph Plus; DiaMondiaL[DML]) for the rapid identification of Staphylococcus aureus. First, comparison with three third-generation assays (Slidex Staph Plus, bioMérieux; Staphaurex Plus, Murex Diagnostics; Pastorex Staph-Plus, Sanofi Diagnostics Pasteur) was performed on a predefined strain collection: 265 coagulase-negative staphylococci (CNS), 266 methicillinresistant S. aureus (MRSA) and 262 methicillin-susceptible S. aureus (MSSA) strains ("strain study"). Second, patient material-derived strains (883 CNS, 847 MSSA and 135 MRSA) were tested concurrently with both the DML and Slidex assays ("daily practice study"). In the strain study, the overall sensitivity and specificity of the DML, Slidex, Staphaurex and Pastorex assays were $99.2 \%$ and $100 \%$, $98.1 \%$ and $100 \%, 95.2 \%$ and $100 \%$, and $98.2 \%$ and $98.8 \%$, respectively. Using the respective tests, the result was indeterminate in $0.0 \%, 0.6 \%, 0.4 \%$ and $1.5 \%$ of the strains. Overall, the sensitivity of the DML and Slidex assays were comparable in both sub-studies. However, in MRSA strains, the sensitivity of the DML assay was significantly lower than the Slidex assay. The specificity of the Slidex assay was significantly higher than the DML assay. However, the percentage of indeterminate results was much higher for the Slidex than the DML assay. In conclusion,
\end{abstract}

G. I. Andriesse $(\bowtie) \cdot S$. Elberts · A. Vrolijk · C. Verhulst

J. A. J. W. Kluytmans

Laboratory for Microbiology and Infection Control,

Amphia Hospital,

Breda, The Netherlands

e-mail: gunnar.andriesse@gmail.com

J. A. J. W. Kluytmans

Medical Microbiology and Infection Control,

VU University Medical Center (VUmc),

Amsterdam, The Netherlands the presumptive identification of $S$. aureus by the DML assay proved to be equal to third-generation latex agglutination assays.

\section{Introduction}

Infections with Staphylococcus aureus are common, both inside and outside the hospital, and can have serious medical consequences if not diagnosed in a timely manner. Therefore, in clinical microbiology laboratories, quick and reliable identification of $S$. aureus is a major quality characteristic. Differentiating S. aureus from other staphylococci has traditionally been done using a coagulase tube test. Although this test is reliable, it takes up to $24 \mathrm{~h}$ to provide results. Since the late 1970s, several alternative procedures have been developed with variable success. In 1980, the first latex agglutination assay with accurate identification of $S$. aureus was introduced by Essers and Radebold [1]. This assay is based on the detection of both coagulase activity (clumping factor) and protein A, both being specific determinants of $S$. aureus. In the last 30 years, several commercial assays based on this principle have been launched. However, certain methicillin-resistant $S$. aureus (MRSA) strains produced false-negative results in some agglutination assays. In an attempt to overcome this problem, third-generation latex agglutination assays have been developed that also detect capsular polysaccharides 5 and 8 , specific antigens present on the surface of up to $80 \%$ of $S$. aureus strains [2]. In effect, the detection of capsular polysaccharides 5 and 8 has been demonstrated to improve the detection of MRSA strains [3].

Recently, the Staph Plus Latex Kit (DiaMondiaL [DML], Sees, France), a new latex agglutination assay for the identification of $S$. aureus, has been marketed. In order to 
further reduce the number of non-specific reactions and, hence, false-negative test results, in this fourth-generation assay, newly developed blue carboxylated microparticles were used in combination with the detection of coagulase, protein A and capsular polysaccharides 5 and 8 .

In this study, we compared the performance of the Staph Plus Latex Kit to three third-generation latex assays (a) on a well-defined collection of staphylococci and (b) in daily practice in a routine microbiology laboratory.

\section{Materials and methods}

In order to analyse both agglutination performance on different individual strains and staphylococcal sub-types versus practical assay performance during daily routine, the evaluation of the DiaMondiaL Staph Plus Latex Kit ${ }^{\mathrm{TM}}$ (DML Staph) was performed in two separate sub-studies: (a) evaluation of the DML Staph performance on a predefined staphylococcal strain collection ("strain study"), comparing DML Staph results to historical data of three third-generation latex agglutination assays, and (b) comparing DML Staph with Slidex Staph Plus on consecutive clinical staphylococcal strains in a routine microbiology laboratory ("daily practice study").

Strain study

The collection of staphylococcal strains used in the strain study was derived from two previously published studies by van Griethuysen et al. [4, 5]. From these studies, historical data were available on the performance of three third-generation latex agglutination assays: (1.) Slidex Staph Plus (bioMérieux), (2.) Staphaurex Plus (Murex Diagnostics) and (3.) Pastorex Staph-Plus (Sanofi Diagnostics Pasteur). In total, 265 coagulase-negative staphylococci (CNS) and 528 S. aureus strains (266 methicillinresistant S. aureus [MRSA] and 262 methicillin-susceptible S. aureus [MSSA]) were conserved and available for use in this study. All isolates were derived from human clinical isolates. Amongst the CNS strains, a wide variety of subspecies were available (Table 1).

All strains were defined in the van Griethuysen et al. studies by the same principle $[4,5]$ : if the tube coagulase test and all three of the above-mentioned latex agglutination tests were positive, the isolate was considered to be $S$. aureus. If all tests were negative, the isolate was considered to be a CNS and further identification to the species level was determined with the ID32 Staph System (bioMérieux). If the results of the tube coagulase test and the latex agglutination tests were discordant, these tests were repeated from a new sub-culture and an ID32 Staph test, and either an AccuProbe culture identification test in one
Table 1 Number of different staphylococcal sub-species among the coagulase-negative strains

\begin{tabular}{ll}
\hline Staphylococcal species & No. tested \\
\hline S. epidermidis & 136 \\
S. hominis & 36 \\
S. lugdunensis & 24 \\
S. capitis & 20 \\
S. warneri & 8 \\
S. xylosus & 5 \\
S. haemolyticus & 5 \\
S. saprophyticus & 4 \\
S. simulans & 2 \\
S. sciuri & 2 \\
S. caprae & 2 \\
S. cohnii & 3 \\
S. auricularis & 1 \\
CNS undetermined & 17 \\
Total & 265 \\
\hline
\end{tabular}

study [5] (Gen-Probe, San Diego, CA, USA) or coagulase gene polymerase chain reaction (PCR) in the other study [4] (see further for specifications) were performed. The result of either the AccuProbe or coagulase gene PCR was considered to be the gold standard. MRSA strains were defined by the presence of the $m e c A$ gene and the coagulase gene by multiplex PCR $[4,5]$.

The collection of strains was stored at $-70^{\circ} \mathrm{C}$ since the year 2000. Shortly before testing, all isolates were subcultured from the $-70^{\circ} \mathrm{C}$ freezer onto Columbia agar $+5 \%$ sheep blood (BioTrading, Mijdrecht, The Netherlands). Subsequently, all strains were sub-cultured one more time on the same media to obtain fresh growth.

The freshly cultured strains were tested using the DML Staph according to the manufacturer's instructions in a random fashion; the performing laboratory physician was not aware of the strain type during testing. The assay consists of a negative control reagent and a test reagent containing blue carboxylated microparticles sensitised with human fibrinogen and monoclonal antibodies for the simultaneous detection of coagulase activity, staphylococcal protein A and capsular polysaccharides 5 and 8. Every strain was tested using a negative control latex reagent to exclude non-specific agglutination. A test was considered to be positive if there was visible agglutination and clearing of the background and no agglutination in the control reagent. One person performed all tests on ten separate days during a 3-week period and the results were recorded on a spreadsheet (Excel).

All isolates with discordant test results of the DML Staph assay were retested for deoxyribonuclease (DNAse) activity (in-house product) [6], coagulase activity (Coagu- 
lase Plasma Rabbit, Becton Dickinson, Bedford, MA, USA), the presence of the mecA gene and $S$. aureusspecific genomic DNA (PCR) to confirm identification of the specific strain. The mecA/S. aureus-PCR was developed in-house and consisted of simultaneous detection (LightCycler 2.0, Roche) of the mecA gene [7] and S. aureusspecific genomic DNA [8]. The primers and probes were designed as follows: $m e c A$ gene (forward primer 5 '-GATCGC-AAC-GGT-CAA-TTT-AAT-TTT-G-3', reverse primer 3'-GCT-TTG-GTC-TTT-CTG-CAT-TCC-T-5' and fluorescent [FAM] TaqMan probe FAM-GGT-ATG-TGG-AAGTTA-GAT-TGG-GAT-CAT-AGC-GTC-BHQ1) and S. aure$u s$-specific genomic DNA (forward primer 5'-CAT-CGGAAA-CAT-TGT-GTT-CTG-TAT-G-3', reverse primer 3'TTT-GGC-TGG-AAA-ATA-TAA-CTC-TCG-TA-3' and Yakima Yellow-labelled TaqMan probe YY-AAG-CCGTCT-TGA-TAA-TCT-TTA-GTA-GTA-CCG-AAG-CTGGT-BHQ1).

For all four latex agglutination assays, the interpretative reading comprised of either a positive, negative or indeterminate test result. If the agglutination was indeterminate, the strain would be excluded from the statistical analysis. Statistical analysis was performed using McNemar's test (two-tailed, GraphPad Inc. Software 2005) and all $p$-values were calculated versus the DML Staph assay.

Daily practice study

During a 3-month period in our clinical microbiology laboratory, presumptive identification of staphylococcal strains was performed by using both the Slidex Staph Plus and the DML Staph assays. All staphylococcal strains from cultures of consecutive clinical specimens were handled according to the laboratories' routine procedures. Both agglutination assays were performed by any of the 30 laboratory physicians during daily practice. All isolates were included based upon the inspection of colony morphology: if a staphylococcal isolate was suspected, both agglutination tests were performed in conjunction with the DNAse test, coagulase test and a cefoxitin disc susceptibility test on a Mueller-Hinton agar plate ( $30 \mu$, cut-off zone $22 \mathrm{~mm}$, Oxoid Ltd., Basingstoke, United Kingdom) or automated susceptibility testing (bioMérieux Vitek, Inc., Hazelwood, MO, USA). Strains with a negative Slidex Staph Plus, DML Staph, DNAse and coagulase test were determined as CNS; strains with a positive result in all tests were determined as $S$. aureus. The determination of MSSA or MRSA was defined by cefoxitin susceptibility or resistance, respectively. All isolates with discordant test results of either agglutination assay, DNAse or coagulase results were retested for DNAse activity, coagulase activity, the presence of the mecA gene and $S$. aureus-specific genomic DNA (PCR) to confirm identification of the specific strain, analogous to the strain

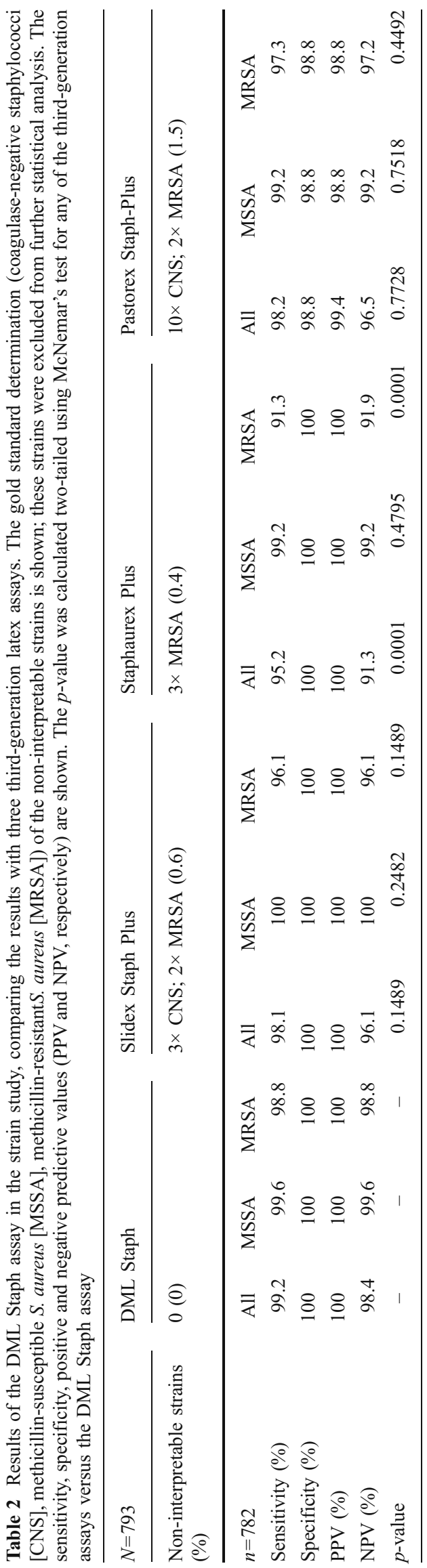


study. Interpretation and statistical analysis was performed analogous to the strain study.

\section{Results}

Strain study

In all isolates tested with the DML Staph assay, a clear interpretational reading of the agglutination could be made (see Table 2). In contrast, in $0.6,0.4$ and $1.5 \%$ of all the strains tested using the Slidex Staph Plus, Staphaurex Plus or Pastorex Staph-Plus assays, respectively, the result was doubtful and no final interpretation could be made. After excluding the strains with indeterminate test results, the results of all four assays were statistically analysed. The overall sensitivity was highest for the DML Staph assay, being 99.2\%. Within the MRSA strains subset, the sensitivity of the DML Staph assay was also the highest (98.8\%) compared to the other assays. However, the sensitivity of the Slidex Staph Plus assay was highest (100\%) among the MSSA strains, followed closely by the DML Staph assay (99.6\%). In the statistical analysis, only the Staphaurex Plus assay sensitivity was significantly lower $(p=0.0001)$. In the sub-analysis, this significantly lower sensitivity could be attributed to a lesser performance in the MRSA strain subset especially.

The specificity of the DML Staph assay was unremarkable $(100 \%)$ for all strains altogether and for MSSA and MRSA strains specifically. A similar specificity was calculated for the Slidex Staph Plus and Staphaurex Plus assays; however, the Pastorex Staph-Plus assay showed a less than perfect specificity (98.8\%).

The DML Staph assay failed to display agglutination in five $S$. aureus strains (false-negatives: one MSSA and four MRSA). Subsequent testing of these strains confirmed the original identification as either MSSA (DNAse-positive, coagulase-positive, mecA gene-negative, $S$. aureus genomic DNA-positive) or MRSA (DNAse-positive, coagulase-

Table 3 Results of the DML Staph assay versus the Slidex Staph Plus assay in the daily practice study. The gold standard determination (CNS, MSSA, MRSA) of the non-interpretable strains is shown; these strains were excluded from further statistical analysis. The sensitivity, positive, mecA gene-positive, S. aureus genomic DNApositive). Between all four latex assays, only the Pastorex Staph-Plus assay had shown false-positive reactions: two $S$. lugdunensis strains and one $S$. capitis strain.

Daily practice study

In total, 1,865 staphylococcal strains (883 CNS, 847 MSSA and 135 MRSA) were tested with both the DML Staph and the Slidex Staph Plus assays (Table 3). Forty-five strains (41 CNS, two MSSA and two MRSA) were excluded from statistical analyses because one or both agglutination tests were indeterminate. The DML Staph assay was indeterminate in 20 strains (1.1\%): $17 \mathrm{CNS}$, one MSSA and two MRSA strains. The Slidex Staph Plus assay was indeterminate in 36 strains (1.9\%): 34 CNS, one MSSA and one MRSA. In 11 CNS strains, both the DML Staph and the Slidex Staph Plus assays were indeterminate.

The overall sensitivity of the DML Staph and the Slidex Staph Plus assays was similar compared to the strain study results. Similarly, the NPV was comparable for both tests in both studies. However, in the MRSA strain subset, the sensitivity of the DML Staph assay was less than that of the Slidex Staph Plus assay, whereas in the strain study, this was the other way around. The specificity of the Slidex Staph Plus assay was significantly higher than that of the DML Staph assay $(p<0.0005)$. Similarly, the PPV of the DML Staph assay was significantly lower than that of the Slidex Staph Plus assay.

The false-positive results in both the DML Staph and the Slidex Staph Plus assays were mostly found in MRSA strains, 5/1 (MRSA/MSSA) and 3/0 (MRSA/MSSA), respectively. In two MRSA strains, both tests produced false-negative results. The DML Staph and the Slidex Staph Plus assays produced false-positive results in 36 and 14 CNS strains, respectively, where all 14 CNS strains were false-positive in both tests.

Remarkably, in 30 CNS strains, the DNAse and coagulase tests were false-positive (negative $S$. aureus/

specificity, PPV and NPV are shown. The $p$-value was calculated twotailed using McNemar's test for the Slidex Staph Plus assay versus the DML Staph assay

\begin{tabular}{|c|c|c|c|c|c|c|}
\hline \multirow{2}{*}{$\frac{N=1,865}{\text { Non-interpretable strains (\%) }}$} & \multicolumn{3}{|c|}{ DML Staph } & \multicolumn{3}{|c|}{ Slidex Staph Plus } \\
\hline & \multicolumn{3}{|c|}{$17 \times \mathrm{CNS} ; 1 \times \operatorname{MSSA} ; 2 \times \operatorname{MRSA}(1.1)$} & \multicolumn{3}{|c|}{$34 \times$ CNS; $1 \times$ MSSA; $1 \times$ MRSA (1.9) } \\
\hline$n=1,820$ & All & MSSA & MRSA & All & MSSA & MRSA \\
\hline Sensitivity (\%) & 99.4 & 99.9 & 96.2 & 99.7 & 100 & 97.7 \\
\hline Specificity (\%) & 95.7 & 95.7 & 95.7 & 98.3 & 98.3 & 98.3 \\
\hline PPV $(\%)$ & 96.4 & 95.9 & 78.1 & 98.6 & 98.4 & 90.3 \\
\hline NPV (\%) & 99.3 & 99.9 & 99.4 & 99.6 & 100 & 99.6 \\
\hline$p$-value & - & - & - & 0.0005 & 0.0000 & 0.0002 \\
\hline
\end{tabular}


mecA PCR), where both the DML Staph and the Slidex Staph Plus assays gave a true-negative result. In 29 cases, this CNS was derived from cultures taken from veterinarians as part of MRSA surveillance.

\section{Discussion}

In 2001, an international multi-centre evaluation of latex agglutination tests for the identification of $S$. aureus was published by van Griethuysen et al. [5]. In that study, the Slidex Staph Plus (bioMérieux) assay was compared to the Staphaurex Plus (Murex Diagnostics) and Pastorex Staph-Plus (Sanofi Diagnostics Pasteur) assays. In addition to clumping factor and protein A, all three assays also detect certain surface antigens: Slidex Staph Plus and Staphaurex Plus detect groupspecific antigens on the $S$. aureus cell surface, and Pastorex Staph-Plus detects capsular polysaccharides 5 and 8. In the strain study, the DML Staph assay (DiaMondiaL) performance was superior compared to the other three latex agglutination assays in differentiating $S$. aureus from CNS, in the same strain collection as used by van Griethuysen et al. The overall sensitivity and specificity of the Slidex Staph Plus assay was comparable; however, in contrast to the DML Staph assay, it failed to produce a definite result in $0.6 \%$ of all isolates. This leads to additional confirmatory testing and costs.

Twenty-nine CNS strains gave false-positive results in the van Griethuysen et al. study [5]. It was suggested that especially $S$. lugdunensis, S. schleiferi and S. haemolyticus were prone to false-positive test results. However, in this study, only three false-positives were found and only when using the Pastorex Staph-Plus assay. Since the van Griethuysen et al. study was an international collaboration, only the Dutch subset of the strain collection originally used was available for this study and, consequently, the number of false-positives cannot be compared. Local epidemiology may affect the performance of diagnostic tests and this should be borne in mind when translating the results of studies into routine diagnostics.

In the strain study, the detection of MSSA strains was very accurate in all four assays. The DML Staph assay performed particularly well in MRSA strains: its sensitivity and specificity was superior compared to the other three assays. In the literature, several reports have suggested that the additional detection of capsular polysaccharides 5 and 8, similar to the DML Staph assay, could explain the better performance of such assays in MRSA strains [2, 9]. However, the Pastorex Staph-Plus assay also detects capsular polysaccharides 5 and 8 , but appeared to be only slightly less effective than the DML Staph assay: the sensitivity in the MRSA strain subset was $97.3 \%$ versus $98.8 \%$, respectively (not significant). The Slidex Staph Plus and Staphaurex Plus assays have also been constructed to detect additional surface antigens of $S$. aureus. In the strain study, both assays performed less well (sensitivity $96.1 \%$ and $91.3 \%$ ) than the DML Staph assay $(98.8 \%)$ in detecting MRSA; however, only for the Staphaurex Plus assay did this reach statistical significance. The microparticles in the DML Staph assay were especially engineered to enhance antibody-antigen complex formation. This may explain the increase in sensitivity compared to the third-generation assays.

In order to rule out observational bias by performing the DML Staph assay by a single person, a secondary study was performed. In this daily practice study, the results of the DML Staph assay were different to in the strain study. In the former, the DML Staph assay appeared superior, whereas in the latter, the Slidex Staph Plus assay performed significantly better. In the daily practice study, differences between the DML Staph and the Slidex Staph Plus assays were almost exclusively attributable to a significant difference in the number of falsepositives: the DML Staph assay displayed positive agglutination in 36 CNS strains versus 14 in the Slidex Staph Plus assay. This is why these agglutination assays should always be used for presumptive identification only and in combination with other tests like DNAse and coagulase tests for definite results. Although the performance of the Slidex Staph Plus assay appeared superior in the daily practice study, in both sub-studies, the number of indeterminate results was considerably higher for the Slidex Staph Plus assay. Taking this into account, in daily practice, the DML Staph and the Slidex Staph Plus assays have equal performance characteristics.

A remarkable subset of 30 CNS strains was found in the daily practice study, where both agglutination assays gave true-negative results in contrast to the DNAse and coagulase tests. All but one of these strains were isolated from veterinarians during a targeted MRSA surveillance project. It is known that $S$. intermedius and $S$. hyicus strains can also secrete coagulase during bacterial growth [10]. Furthermore, S. intermedius and S. hyicus are well known for their pathogenicity in animals but not in humans [11].

Overall, the results of the fourth-generation latex agglutination assay proved to be comparable to third-generation assays, both in terms of sensitivity and specificity and ease to identify $S$. aureus strains.

Open Access This article is distributed under the terms of the Creative Commons Attribution Noncommercial License which permits any noncommercial use, distribution, and reproduction in any medium, provided the original author(s) and source are credited.

\section{References}

1. Essers L, Radebold K (1980) Rapid and reliable identification of Staphylococcus aureus by a latex agglutination test. J Clin Microbiol 12:641-643

2. Verdier I, Durand G, Bes M, Taylor KL, Lina G, Vandenesch F, Fattom AI, Etienne J (2007) Identification of the capsular 
polysaccharides in Staphylococcus aureus clinical isolates by PCR and agglutination tests. J Clin Microbiol 45:725-729

3. Fournier JM, Bouvet A, Mathieu D, Nato F, Boutonnier A, Gerbal R, Brunengo P, Saulnier C, Sagot N, Slizewicz B (1993) New latex reagent using monoclonal antibodies to capsular polysaccharide for reliable identification of both oxacillin-susceptible and oxacillinresistant Staphylococcus aureus. J Clin Microbiol 31:1342-1344

4. van Griethuysen A, Pouw M, van Leeuwen N, Heck M, Willemse P, Buiting A, Kluytmans J (1999) Rapid slide latex agglutination test for detection of methicillin resistance in Staphylococcus aureus. J Clin Microbiol 37:2789-2792

5. van Griethuysen A, Bes M, Etienne J, Zbinden R, Kluytmans J (2001) International multicenter evaluation of latex agglutination tests for identification of Staphylococcus aureus. J Clin Microbiol 39:86-89

6. Jeffries CD, Holtman DF, Guse DG (1957) Rapid method for determining the activity of microorganisms on nucleic acids. J Bacteriol 73:590-591
7. Ryffel C, Tesch W, Birch-Machin I, Reynolds PE, Barberis-Maino L, Kayser FH, Berger-Bächi B (1990) Sequence comparison of mecA genes isolated from methicillin-resistant Staphylococcus aureus and Staphylococcus epidermidis. Gene 94:137-138

8. Martineau F, Picard FJ, Roy PH, Ouellette M, Bergeron MG (1998) Species-specific and ubiquitous-DNA-based assays for rapid identification of Staphylococcus aureus. J Clin Microbiol 36:618-623

9. Fournier JM, Boutonnier A, Bouvet A (1989) Staphylococcus aureus strains which are not identified by rapid agglutination methods are of capsular serotype 5. J Clin Microbiol 27:1372-1374

10. Murray PR (2007) Manual of clinical microbiology, 9th edn. ASM Press, Washington

11. Phillips WE Jr, Kloos WE (1981) Identification of coagulasepositive Staphylococcus intermedius and Staphylococcus hyicus subsp. hyicus isolates from veterinary clinical specimens. J Clin Microbiol 14:671-673 